\title{
INVERSE PROBLEMS FOR SOME SOBOLEV-TYPE MATHEMATICAL MODELS
}

S.G. Pyatkov, Ugra State University, Khanty-Mansyisk, Russian Federation, S_pyatkov@ugrasu.ru,

S.N. Shergin, Ugra State University, Khanty-Mansyisk, Russian Federation, Ssn@ugrasu.ru

The present article is devoted to the study of mathematical models based the Sobolevtype equations and systems arising in dynamics of a stratified fluid, elasticity theory, hydrodynamics, electrodynamics, etc. Along with a solution we determine an unknown right-hand side and coefficients in a Sobolev-type equations of the forth order. The overdetermination conditions are the values of a solution in a collection of points of a spatial domain. The problem is reduced to an operator equation whose solvability is established with the help of a priori estimates and the fixed point theorem. The existence and uniqueness theorems of solutions for the linear and nonlinear cases are proven. In the linear case the result is global in time and it is local in the nonlinear case. The main spaces in question are the Sobolev spaces.

Keywords: the Sobolev-type model; Sobolev equation; existence and uniqueness theorems; inverse problem; boundary value problem; plasma waves; rotating fluid; the Boussinesq - Love model.

\section{Introduction}

We consider the problem on determining a solution $U$, the right-hand side, and coefficients in the equation

$$
L_{0} U_{t t}+L_{1} U_{t}+L_{2} U=f, \quad(x, t) \in Q=G \times(0, T),
$$

where $L_{i}(i=0,1,2)$ are second order operators in the variables $x, G$ is a bounded domain in $R^{n}(n \geq 1)$ with boundary $\Gamma \in C^{2}$. The equation is supplemented with the following initial an boundary conditions:

$$
\begin{gathered}
\left.U\right|_{S}=\varphi, \quad S=\Gamma \times(0, T), \\
\left.U\right|_{t=0}=U_{0}(x),\left.\quad U_{t}\right|_{t=0}=U_{1}(x) .
\end{gathered}
$$

We assume that the right-hand side in (1) is of the form

$$
f=\sum_{i=1}^{m} c_{i}(t) f_{i}(x, t)+f_{0}(x, t),
$$

where the functions $f_{i}(i=0,1, \ldots, m)$ are given. The problem is to find the right-hand side $f$ (i.e. the functions $\left.c_{i}(t)\right)$ ) and coefficients of (1) dependent on time with the use of the overdetermination conditions being the values of a solution $U$ at separate points. Thus, the overdetermination conditions are as follows:

$$
U\left(x_{i}, t\right)=\psi_{i}(t), \quad(i=1,2, . ., m),
$$


with $x_{i}$ arbitrary points of $G$. Mathematical models relying on the Sobolev-type equations of the form (3) arise in many fields of mathematical physics, in particular, in elasticity theory, hydrodynamics, and electrodynamics. The class of equations (1) contains the classical Sobolev equation describing small oscillations of a rotating fluid [1], the Boussinesq - Love model describing the shallow-water waves [2] and longitudinal oscillations of an elastic rod [3] (see also the monograph [4]), and the models describing linear waves in a nonmagnetized plasma (see [5]). The inverse problems for the Sobolevtype equations are not studied well. The main attention in the previous articles was paid to the equations of the third order, i.e. the pseudoparabolic equations. Describe some results. The inverse problem of recovering a leading coefficient in a pseudoparabolic equation with the use of an integral overdetermination condition on the boundary of the domain is studied in several articles by A.Sh. Lyubanova and E.A. Tani [6, 7]. They establish local existence and uniqueness theorems and derive some properties of solutions to inverse problems of this type. Close results but with different overdetermination conditions are exposed in $[8-10,11]$. Some inverse problems for pseudoparabolic equations are presented in the monograph [12]. The problem of recovering a kernel of an integral operator occurring in Sobolev-type equations when some functional of a solution is examined in [13]. Close results are presented in [14]. In the case of forth order models (1), only some particular results are known. Optimal control problems for the Boussinesq - Love model are examined in [15-17]. Some inverse problems, one of which is included in our class of inverse problems (1) - (5), for one-dimensional Boussinesq - Love model is treated in [18,19], where the study of existence of a solution is reduced to a system of integral equations. Similar existence theorems in the one-dimensional case are exposed in [20]. Here several inverse problems are stated. They differ in the overdetermination conditions; an integral condition, the Cauchy data, the final overdetermination condition, and the condition of the form (5) with $m=1$.

In contrast to the previous results, we consider a more general class of multidimensional models with an arbitrary number of conditions (5). In this case the right-hand side can be treated as an approximation of an arbitrary function $f(t, x)$ by a finite segment of a series. In the article we consider the linear case, i.e. the problem on determination of the right-hand side and nonlinear, i.e. the coefficient problem. The main results are Theorems 3 and 4 stating that in both cases the problem (1) - (5) is well-posed. In the linear case the result is global in time and respectively local in the nonlinear case.

\section{Preliminaries}

We employ the Sobolev spaces $W_{p}^{s}(G)$ and the Hölder spaces $C^{\alpha}(\bar{G})$ (see the definitions in [21]). The symbol $L_{p}(0, T ; H)(H$ is a Banach space) designates the space of strongly measurable functions defined on $[0, T]$ with values in $H$. Below we assume that $\Gamma \in C^{2}$ (see the definition, for example, in Sect. 1, Ch. 1 of [21]), the operators $L_{k}(k=0,1,2)$ are of the form

$$
L_{k} U=\sum_{i, j=1}^{m} a_{i j}^{k}(x, t) U_{x_{i} x_{j}}+\sum_{i=1}^{m} a_{i}^{k}(x, t) U_{x_{i}}+a_{0}^{k}(x, t) U
$$

with real coefficients, and $L_{0}$ is an elliptic operator, i.e., there exists a constant $\delta_{0}>0$ such that

$$
\sum_{i, j=1}^{m} a_{i j}^{0} \xi_{i} \xi_{j} \geq \delta_{0}|\xi|^{2} \quad \forall \xi \in R^{n}, \quad \forall(x, t) \in \bar{Q} .
$$


Fix a parameter $p>n$ and assume that

$$
\begin{gathered}
a_{i j}^{0} \in C(\bar{Q}), \quad a_{i}^{0}, a_{0}^{0} \in C\left([0, T] ; L_{p}(G)\right), a_{0}^{0}(x, t) \leq 0 \quad \text { a.e. in } Q \\
a_{i j}^{k} \in L_{p}\left(0, T ; L_{\infty}(G)\right), \quad a_{i}^{k}, a_{0}^{k} \in L_{p}(Q) \quad(i, j=1,2, . ., n, k=1,2) .
\end{gathered}
$$

Under these conditions on the coefficients of $L_{0}$ the following theorem is valid.

Theorem 1. The Dirichlet problem

$$
L_{0} u=f,\left.\quad u\right|_{\Gamma}=0,
$$

for every $f \in L_{q}\left(0, T ; L_{p}(G)\right)(p>n, q \in[1, \infty])$ has a unique solution $u \in$ $L_{q}\left(0, T ; W_{p}^{2}(G)\right)$ satisfying the estimate

$$
\|u\|_{L_{q}\left(0, T ; W_{p}^{2}(G)\right)} \leq c\|f\|_{L_{q}\left(0, T ; L_{p}(G)\right)}
$$

where $c$ is independent of $f$.

Proof. The solvability of problem (7) (depending on the parameter $t$ ) results from uniqueness of solutions (see the maximum principle in Ch. 9 of [22]) and the Fredholm property of these problems. Estimates for solutions can be obtained with the use of the fact that the coefficients of the operator are continuous in $t$ and thus in some neighborhood of every point $t_{0} \in[0, T]$, we can prove an estimate of the form $\|u\|_{W_{p}^{2}(G)} \leq c\left\|L_{0} u\right\|_{L_{p}(G)}$ with a constant $c$ independent of $t$. These estimates ensure the global estimate from the claim of the theorem.

Lemma 1. If $b \in L_{q}(G)$ with $q>n$ for $p \leq n$ and $q \geq p$ for $p>n$ then there exists a constant $c>0$ such that

$$
\|b \nabla U\|_{L_{p}(G)} \leq c\|U\|_{W_{p}^{2}(G)} \quad \forall U \in W_{p}^{2}(G) .
$$

If $b \in L_{q}(G)$ with $q>n / 2$ for $p \leq n / 2$ and $q \geq p$ for $p>n / 2$ then there exists a constant $c>0$ such that

$$
\|b U\|_{L_{p}(G)} \leq c\|U\|_{W_{p}^{2}(G)} \quad \forall U \in W_{p}^{2}(G) .
$$

Proof. The proof coincides with that of Lemma 1 in [23].

Theorem 2. Assume that $\varphi, \varphi_{t}, \varphi_{t t} \in L_{p}\left(0, T ; W_{p}^{2-1 / p}(G)\right)(p \in(1, \infty)), f \in L_{p}(Q)$, $U_{i}(x) \in W_{p}^{2}(G)(i=0,1)$, conditions (6) for the coefficients and the agreement conditions

$$
\left.\varphi(x, 0)\right|_{\Gamma}=\left.U_{0}(x)\right|_{\Gamma},\left.\quad \varphi_{t}(x, 0)\right|_{\Gamma}=\left.U_{1}(x)\right|_{\Gamma}
$$

hold. Then there exists a unique solution to (1) - (3) such that $U_{t t} \in L_{p}\left(0, T ; W_{p}^{2}(G)\right)$, $U, U_{t} \in C\left([0, T] ; W_{p}^{2}(G)\right)$. If $\varphi \equiv 0, U_{i}(x) \equiv 0(i=0,1)$ then there exists a constant $c>0$ independent of $\gamma \in(0, T]$ and $f$ such that a solution to the problem (1) - (3) satisfies the estimate

$$
\|U\|_{L_{\infty}\left(0, \gamma ; W_{p}^{2}(G)\right)}+\left\|U_{t}\right\|_{L_{\infty}\left(0, \gamma ; W_{p}^{2}(G)\right)}+\left\|U_{t t}\right\|_{L_{p}\left(0, \gamma ; W_{p}^{2}(G)\right)} \leq c\|f\|_{L_{p}\left(Q^{\gamma}\right)}\left(Q^{\gamma}=G \times(0, \gamma)\right) .
$$


Proof. Consider the segment $[0, T]$. Find a function $\Phi$ such that

$$
\Phi, \Phi_{t}, \Phi_{t t} \in L_{p}\left(0, T ; W_{p}^{2}(G)\right):\left.\Phi\right|_{S}=\varphi,\left.\quad \Phi\right|_{t=0}=U_{0}(x),\left.\quad \Phi_{t}\right|_{t=0}=U_{1}(x),
$$

which can be constructed as follows:

$$
\Phi=\psi+U_{0}+t U_{1}(x), \quad \psi=\int_{0}^{t} \int_{0}^{\xi} \psi_{0}(x, \tau) d \tau d \xi, \quad \Delta \psi_{0}=0,\left.\quad \psi_{0}\right|_{\Gamma}=\varphi_{t t}
$$

(the existence of a function $\psi_{0}$ follows from the well-known results, see, for instance, [22]). The function $V=U-\Phi$ is a solution to the problem

$$
L_{0} V_{t t}+L_{1} V_{t}+L_{2} V=f-L_{0} \Phi_{t t}-L_{1} \Phi_{t}-L_{2} \Phi=g,\left.\quad V\right|_{S}=0,\left.\quad V\right|_{t=0}=0,\left.\quad V_{t}\right|_{t=0}=0 .
$$

Theorem 1 yields

$$
V+\int_{0}^{t} \int_{0}^{\xi} L_{0}^{-1}\left(L_{1} V_{t}(\tau, x)+L_{2} V(\tau, x)\right) d \tau d \xi=\int_{0}^{t} \int_{0}^{\xi} L_{0}^{-1} g(\tau, x) d \tau d \xi .
$$

Condition (6) and Lemma 1 validate the estimate $(\tau \leq T)$

$$
\left\|L_{0}^{-1} L_{i} V\right\|_{L_{q}\left(0, \tau ; W_{p}^{2}(G)\right)} \leq c\|V\|_{L_{q}\left(0, \tau ; W_{p}^{2}(G)\right)}, \quad q \in[1, \infty],
$$

which for $q=\infty$ along with the fixed point theorem allows us to justify the existence theorem. The estimate from the claim is proven by analogy with that in Theorem 2 in [23].

\section{Basic Results}

\subsection{The Linear Case}

Write out the conditions on the data of the problem. In addition to the agreement conditions (10) we require that

$$
\psi_{i}(0)=U_{0}\left(x_{i}\right), \quad \psi_{i t}(0)=U_{1}\left(x_{i}\right), \quad i=1,2, \ldots, m .
$$

The well-posedness condition. Denote by $B$ the matrix with the entries $b_{i j}=$ $L_{0}^{-1} f_{i}\left(x_{j}, t\right)$ and assume that there exists $\delta_{0}>0$ such that

$$
|\operatorname{det} B| \geq \delta_{0} \quad \forall t \in[0, T]
$$

where $L_{0}^{-1} f_{i}$ is a solution $U_{i}$ to the problem $L_{0} U_{i}=f_{i},\left.\quad U_{i}\right|_{S}=0$.

Theorem 3. Assume that the coefficients of the operators $L_{i}(i=0,1,2)$ satisfy conditions (6), the agreement conditions (10), (12) and the well-posedness condition (13) are fulfilled, and

$f_{0} \in L_{p}(Q), f_{i} \in L_{\infty}\left(0, T ; L_{p}(G)\right), U_{j} \in W_{p}^{2}(G)(j=0,1), \varphi, \varphi_{t}, \varphi_{t t} \in L_{p}\left(0, T ; W_{p}^{2-1 / p}(G)\right)$,

$$
\psi_{i} \in W_{p}^{2}(0, T), i=1,2, \ldots, m, \quad p>n .
$$

Then there exists a unique solution to (1) - (5) such that

$$
U, U_{t} \in C\left([0, T] ; W_{p}^{2}(G)\right), U_{t t} \in L_{p}\left(0, T ; W_{p}^{2}(G)\right), \quad c_{i} \in L_{p}(0, T), \quad(i=1,2, . ., m) .
$$


Proof. As in the proof of Theorem 2, we construct a function $\Phi(x, t)$ such that $\Phi, \Phi_{t}, \Phi_{t t} \in$ $L_{p}\left(0, T ; W_{p}^{2}(G)\right),\left.\Phi\right|_{S}=\varphi,\left.\Phi\right|_{t=0}=U_{0}(x),\left.\Phi_{t}\right|_{t=0}=U_{1}(x)$. The function $V=U-\Phi$ is a solution to the problem

$$
\begin{gathered}
L_{0} V_{t t}+L_{1} V_{t}+L_{2} V=f_{0}-L_{0} \Phi_{t t}-L_{1} \Phi_{t}-L_{2} \Phi+\sum_{i=1}^{m} c_{i} f_{i}=g_{0}+\sum_{i=1}^{m} c_{i} f_{i}, \\
V\left(x_{i}, t\right)=U\left(x_{i}, t\right)-\Phi\left(x_{i}, t\right)=\psi_{i}-\Phi\left(x_{i}, t\right)=\varphi_{i}(t), \\
\left.V\right|_{S}=0,\left.\quad V\right|_{t=0}=0,\left.\quad V_{t}\right|_{t=0}=0 .
\end{gathered}
$$

Inverting $L_{0}$ we obtain that

$$
V_{t t}+L_{0}^{-1} L_{1} V_{t}+L_{0}^{-1} L_{2} V=L_{0}^{-1} g_{0}+\sum_{i=1}^{m} c_{i} L_{0}^{-1} f_{i}
$$

where the operator $L_{0}^{-1}$ takes a function $g$ into a solution to the problem

$$
L_{0} V=g,\left.\quad V\right|_{S}=0,\left.\quad V\right|_{t=0}=0,\left.\quad V_{t}\right|_{t=0}=0 .
$$

Since $\Phi \in W_{p}^{2}\left(G ; W_{p}^{2}(0, T)\right.$ ) and thereby, (since $p>n$ ) changing it on a set of zero measure if necessary, we can assume that $\Phi \in C^{1}\left(\bar{G} ; W_{p}^{2}(0, T)\right)$ (see [24]). Therefore, $\Phi\left(x_{i}, \cdot\right) \in W_{p}^{2}(0, T)$, in this case $\varphi_{i} \in W_{p}^{2}(0, T)$. Putting $x=x_{i}$, we have

$\varphi_{i t t}+L_{0}^{-1} L_{1} V_{t}\left(x_{i}, t\right)+L_{0}^{-1} L_{2} V\left(x_{i}, t\right)=L_{0}^{-1} g_{0}\left(x_{i}, t\right)+\sum_{j=1}^{m}\left(L_{0}^{-1} f_{j}\right)\left(x_{i}, t\right) c_{j}(t), i=1, \ldots, m$.

This equality and condition (13) yield

$$
\vec{c}=B^{-1}\left(\begin{array}{c}
\varphi_{1 t t}+L_{0}^{-1} L_{1} V_{t}\left(x_{1}, t\right)+L_{0}^{-1} L_{2} V\left(x_{1}, t\right)-L_{0}^{-1} g_{0}\left(x_{1}, t\right) \\
\cdots \\
\cdots \\
\varphi_{m t t}+L_{0}^{-1} L_{1} V_{t}\left(x_{m}, t\right)+L_{0}^{-1} L_{2} V\left(x_{m}, t\right)-L_{0}^{-1} g_{0}\left(x_{m}, t\right)
\end{array}\right), \quad \vec{c}=\left(\begin{array}{c}
c_{1} \\
\cdot \\
\cdot \\
c_{m}
\end{array}\right) .
$$

The latter equality is an operator equation for the vector-function $\vec{c}=\left(c_{1}, c_{2}, . ., c_{m}\right)$, where $V=V(c)$ is an operator taking $\vec{c}$ into a solution to the problem

$$
A_{0} V=L_{0} V_{t t}+L_{1} V_{t}+L_{2} V=g_{0}+\sum_{i=1}^{m} c_{i} f_{i},\left.V\right|_{S}=0,\left.\quad V\right|_{t=0}=0,\left.\quad V_{t}\right|_{t=0}=0 .
$$

The function $V$ is representable as $V=A_{0}^{-1} g_{0}+A_{0}^{-1}\left(\sum_{i=1}^{m} c_{i} f_{i}\right)=V_{0}+A_{0}^{-1}\left(\sum_{i=1}^{m} c_{i} f_{i}\right)$. Thus, we can rewrite the system for the vector-function $\vec{c}$ in the form

$$
\overrightarrow{c_{0}=B^{-1}\left(\begin{array}{c}
\vec{c}=\overrightarrow{c_{0}}+R(\vec{c}) \\
\varphi_{1 t t}+L_{0}^{-1}\left(L_{1} V_{0 t}\left(x_{1}, t\right)+L_{2} V_{0}\left(x_{1}, t\right)\right)-L_{0}^{-1} g_{0}\left(x_{1}, t\right) \\
\cdots \\
\cdots \\
\varphi_{m t t}+L_{0}^{-1}\left(L_{1} V_{0 t}\left(x_{m}, t\right)+L_{2} V_{0}\left(x_{m}, t\right)\right)-L_{0}^{-1} g_{0}\left(x_{m}, t\right)
\end{array}\right),}
$$




$$
R(\vec{c})=B^{-1}\left(\begin{array}{c}
L_{0}^{-1}\left(L_{1} \partial_{t}+L_{2}\right) A_{0}^{-1} \sum_{i=1}^{m} c_{i} f_{i}\left(x_{1}, t\right) \\
\ldots \\
\cdots \\
L_{0}^{-1}\left(L_{1} \partial_{t}+L_{2}\right) A_{0}^{-1} \sum_{i=1}^{m} c_{i} f_{i}\left(x_{m}, t\right)
\end{array}\right)
$$

Note that the functions $L_{0}^{-1} f_{i}\left(x_{j}, t\right)$ belong to $L_{\infty}(0, T)$. Indeed, $f_{i} \in L_{\infty}\left(0, T ; L_{p}(G)\right)$ and $L^{-1} f_{i} \in L_{\infty}\left(0, T ; W_{p}^{2}(G)\right)$. Therefore, for almost all $t L^{-1} f_{i} \in W_{p}^{2}(G)$. The embedding theorems (see, for instance, [21]) and the condition $p>n$ imply that the function $L_{0}^{-1} f_{i}(x, t)$ is continuous in $x$ after a possible modification on a set of zero measure and we have

$$
\left\|L_{0}^{-1} f_{i}\left(x_{j}, t\right)\right\|_{L_{\infty}(0, T)} \leq C\left\|L_{0}^{-1} f_{i}(x, t)\right\|_{L_{\infty}\left(0, T ; W_{p}^{2}(G)\right)} \leq C_{1}\left\|f_{i}\right\|_{L_{\infty}\left(0, T ; L_{p}(G)\right)} .
$$

As easily seen, the estimate $\left\|B^{-1} \vec{g}(t)\right\|_{L_{p}(0, \gamma)} \leq C\|\vec{g}(t)\|_{L_{p}(0, \gamma)}$, is valid for every $\vec{g} \in L_{p}(0, \gamma)$ and $\gamma \in[0, T]$ with a constant $C$ independent of $\gamma$. Thus, we have

$$
\|R(\vec{c})\|_{L_{p}(0, \gamma)} \leq C_{2} \sum_{j=1}^{m}\left\|L_{0}^{-1}\left(L_{1} \partial_{t}+L_{2}\right) A_{0}^{-1}\left(\sum_{i=1}^{m} c_{i} f_{i}\right)\left(x_{j}, t\right)\right\|_{L_{p}(0, \gamma)} .
$$

In view of embedding theorems and Theorem 2 the right-hand side is estimated by the quantity

$$
\begin{gathered}
C_{2} \sum_{j=1}^{m}\left\|L_{0}^{-1}\left(L_{1} \partial_{t}+L_{2}\right) A_{0}^{-1}\left(\sum_{i=1}^{m} c_{i} f_{i}\right)\right\|_{L_{p}\left(0, \gamma ; W_{p}^{2}(G)\right)} \leq C_{3}\left\|\left(L_{1} \partial_{t}+L_{2}\right) A_{0}^{-1}\left(\sum_{i=1}^{m} c_{i} f_{i}\right)\right\|_{L_{p}\left(0, \gamma ; L_{p}(G)\right)} \leq \\
\leq C_{3} \gamma^{1 / p}\left\|\left(L_{1} \partial_{t}+L_{2}\right) A_{0}^{-1}\left(\sum c_{i} f_{i}\right)\right\|_{L_{\infty}\left(0, \gamma ; L_{p}(G)\right)} \leq C_{4} \gamma^{1 / p}\left\|\sum_{i=1}^{m} c_{i} f_{i}\right\|_{L_{p}\left(Q^{\gamma}\right)} .
\end{gathered}
$$

The right-hand side here is estimated by $C_{5} \gamma^{1 / p} \sum_{i=1}^{m}\left\|c_{i} f_{i}\right\|_{L_{p}\left(Q^{\gamma}\right)}$ and

$$
\left\|c_{i} f_{i}\right\|_{L_{p}\left(Q^{\gamma}\right)}=\left(\int_{0}^{\gamma}\left|c_{i}\right|^{p}(t) \int_{G}\left|f_{i}\right|^{p}(x, t) d x d t\right)^{1 / p} \leq\left\|f_{i}\right\|_{L_{\infty}\left(0, T ; L_{p}(G)\right)}\left(\int_{0}^{\gamma}\left|c_{i}\right|^{p}(t) d t\right)^{1 / p} .
$$

Taking the above inequalities into account, we arrive at the estimate

$$
\|R(\vec{c})\|_{L_{p}(0, \gamma)} \leq C_{7} \gamma^{1 / p}\|\vec{c}\|_{L_{p}(0, T)}
$$

where $C_{7}$ is independent of $\gamma$. Thereby, if $C_{7} \gamma^{1 / p}=q_{0}<1$ then equation (17) is uniquely solvable. Fix a constant $\gamma$ satisfying this condition and examine the equation

$$
\vec{c}-R(\vec{c})=\vec{c}_{0}
$$

We can assume without loss of generality that all constants used in the proof of (18) are independent of $\gamma$. Let $\vec{c}$ be a solution to (17) defined on $[0, \gamma]$. Construct the vector $\vec{c}_{1}=\left\{\begin{array}{ll}\vec{c}, & t \leq \gamma \\ 0, & t>\gamma .\end{array}\right.$ Make the change $\vec{k}_{1}=\vec{c}-\vec{c}_{1}\left(\vec{k}_{1}=\left(k^{1}, k^{2}, \ldots, k^{m}\right)\right)$ in (19); if $\vec{c}$ is a 
solution to (19) on $[0,2 \gamma]$ then $\vec{k}_{1}=0$ for $t \leq \gamma$ and $\vec{k}_{1}-R\left(\vec{k}_{1}\right)=\vec{c}_{0}-\vec{c}_{1}+R\left(\vec{c}_{1}\right)$. The right-hand side here vanishes on $[0, \gamma]$ and, respectively, $R\left(\vec{k}_{1}\right)=0$ for $t \leq \gamma$.

We can solve the system

$$
\vec{k}_{1}-R\left(\vec{k}_{1}\right)=\vec{c}_{0}-\vec{c}_{1}+R\left(\vec{c}_{1}\right)
$$

on $[\gamma, 2 \gamma]$. Indeed, if $\vec{k}_{1} \in L_{p}(0,2 \gamma)$ then repeating the above argument we establish the estimate

$$
\begin{gathered}
\left\|R\left(\vec{k}_{1}\right)\right\|_{L_{p}(\gamma, 2 \gamma)} \leq C \sum_{j=1}^{m}\left\|L_{0}^{-1}\left(L_{1} \partial_{t}+L_{2}\right) A_{0}^{-1}\left(\sum_{i=1}^{m} k^{i} f_{i}\right)\left(x_{j}, t\right)\right\|_{L_{p}(\gamma, 2 \gamma)} \leq \\
\leq C_{2} \sum_{j=1}^{m}\left\|L_{0}^{-1}\left(L_{1} \partial_{t}+L_{2}\right) A_{0}^{-1}\left(\sum_{i=1}^{m} k^{i} f_{i}\right)\right\|_{L_{p}\left(\gamma, 2 \gamma ; W_{p}^{2}(G)\right)} \leq \\
\leq C_{3}\left\|\left(L_{1} \partial_{t}+L_{2}\right) A_{0}^{-1}\left(\sum_{i=1}^{m} k^{i} f_{i}\right)\right\|_{L_{p}\left(\gamma, 2 \gamma ; L_{p}(G)\right)} \leq \\
\leq C_{3} \gamma^{1 / p}\left\|\left(L_{1} \partial_{t}+L_{2}\right) A_{0}^{-1}\left(\sum_{i=1}^{m} k^{i} f_{i}\right)\right\|_{L_{\infty}\left(\gamma, 2 \gamma ; L_{p}(G)\right)} \leq C_{7} \gamma^{1 / p} \sum_{i=1}^{m}\left\|k^{i}\right\|_{L_{p}(\gamma, 2 \gamma)} .
\end{gathered}
$$

The final estimate is of the form

$$
\left\|R\left(\vec{k}_{1}\right)\right\|_{L_{p}(\gamma, 2 \gamma)} \leq C_{7} \gamma^{1 / p}\left\|\vec{k}_{1}\right\|_{L_{p}(\gamma, 2 \gamma)}
$$

where, without loss of generality, we can assume that $C_{7}$ is the same constant as that in (18). Thus, equation (20) has a unique solution $\vec{k}_{1} \in L_{p}(0,2 \gamma)$ such that $\vec{k}_{1}=0$ for $t \in(0, \gamma)$. Hence, the function $\vec{c}=\vec{c}_{1}+\vec{k}_{1}$ is a solution to (17) from $L_{p}(0,2 \gamma)$. Repeating the arguments, we can construct a solution $\vec{c}$ to equation (17) on the whole segment $[0, T]$.

Construct a function $V$ as a solution to (16). Demonstrate that $V$ satisfies (14). Inverting $L_{0}$ we obtain that $V$ satisfies (15). Taking $x=x_{i}$ in (15), we infer

$$
V_{t t}\left(x_{i}, t\right)+L_{0}^{-1}\left(L_{1} \partial_{t}+L_{2}\right) V\left(x_{i}, t\right)=L_{0}^{-1} g_{0}\left(x_{i}, t\right)+\sum_{j=1}^{m} L_{0}^{-1} c_{j}(t) f_{j}\left(x_{i}, t\right) .
$$

But the vector-function $\vec{c}$ is such that

$$
\varphi_{i t t}(t)+L_{0}^{-1}\left(L_{1} \partial_{t}+L_{2}\right) V\left(x_{i}, t\right)=L_{0}^{-1} g_{0}\left(x_{i}, t\right)+\sum_{j=1}^{m} L_{0}^{-1} c_{j}(t) f_{j}\left(x_{i}, t\right) .
$$

Subtracting these equalities we obtain $V_{t t}\left(x_{i}, t\right)-\varphi_{i t t}(t)=0$ or $\partial_{t}^{2}\left(V\left(x_{i}, t\right)-\varphi_{i}(t)\right)=0$. Integrating from zero to $t$ twice and involving the agreement conditions we obtain that $V\left(x_{i}, t\right)-\varphi_{i}(t)=0$. Thus, $V\left(x_{i}, t\right)=\varphi_{i}(t) \quad \forall i=1,2, \ldots, m$.

\subsection{Nonlinear Case}

Let the right-hand side in (1) and the operators $L_{s}(s=1,2)$ be of the form

$$
f=\sum_{i=1}^{r_{0}} c_{i}(t) f_{i}(x, t)+f_{0}(x, t)
$$




$$
L_{s} U=L_{0 s} U+\sum_{k=r_{s-1}+1}^{r_{s}} c_{k}(t) L^{k} U, L^{k} U=\sum_{i, j=1}^{n} a_{i j}^{k}(x, t) U_{x_{i} x_{j}}+\sum_{i=1}^{n} a_{i}^{k}(x, t) U_{x_{i}}+a_{0}^{k}(x, t) U .
$$

The overdetermination conditions are as follows:

$$
\left.U\right|_{x=x_{i}}=\alpha_{i}(t), \quad \alpha_{i}(t) \in W_{p}^{2}(0, T), \quad x_{i} \in G,\left(i=1,2, . ., r_{2}\right) .
$$

The agreement conditions are written as

$$
\alpha_{i}(0)=U_{0}\left(x_{i}, t\right), \quad \alpha_{i t}(0)=U_{1}\left(x_{i}, t\right) \quad\left(i=1,2, . ., r_{2}\right) .
$$

Let a function $\Phi \in C^{1}\left([0, T] ; W_{p}^{2}(G)\right)(p>n)$ is such that $\Phi_{t t} \in L_{p}\left(0, T ; W_{p}^{2}(G)\right),\left.\Phi\right|_{t=0}=$ $U_{0}(x),\left.\Phi_{t}\right|_{t=0}=U_{1}(x),\left.\Phi\right|_{t=0}=U_{0}(x),\left.\Phi\right|_{S}=\varphi$. Construct a matrix $B$ with rows

$$
\begin{gathered}
L_{0}^{-1} f_{1}\left(x_{j}, t\right), L_{0}^{-1} f_{2}\left(x_{j}, t\right), \ldots, L_{0}^{-1} f_{r_{0}}\left(x_{j}, t\right),-L_{0}^{-1} L^{r_{0}+1} \Phi_{t}\left(x_{j}, t\right), \ldots,-L_{0}^{-1} L^{r_{1}} \Phi_{t}\left(x_{j}, t\right), \\
-L_{0}^{-1} L^{r_{1}+1} \Phi\left(x_{j}, t\right), \ldots,-L_{0}^{-1} L^{r_{2}} \Phi\left(x_{j}, t\right), j=1,2, \ldots, r_{2},
\end{gathered}
$$

and assume that there exists a constant $\delta_{0}>0$ such that

$$
|\operatorname{det} B| \geq \delta_{0} \quad \forall t \in[0, T]
$$

where $L_{0}^{-1} f_{i}$ is a solution $U_{i}$ to the problem $L_{0} U_{i}=f_{i},\left.U_{i}\right|_{S}=0$. It is easy to justify that locally in time condition (26) is independent of the choice of $\Phi$ under the conditions of the theorem below.

The condition (A). The operator $L_{0}$ is a second order elliptic operator and its coefficients satisfy the first condition in (6), the operators $L_{01}, L_{02}$ are of the same form as $L_{1}, L_{2}$ from the previous section and their coefficients satisfy the second condition in (6). The coefficients of the operators $L^{k}\left(k=r_{0}+1, \ldots, r_{2}\right)$ satisfy the relations

$$
a_{i j}^{k} \in L_{\infty}(Q), \quad(i, j=1,2, . ., n), \quad a_{i}^{k}, a_{0}^{k} \in L_{\infty}\left(0, T ; L_{p}(G)\right), k=r_{0}+1, \ldots, r_{2} .
$$

Theorem 4. Assume that condition (A), the agreement conditions (25) and (10), and the well-posedness conditions (26) hold and

$$
\begin{gathered}
f_{0} \in L_{p}(Q), f_{i} \in L_{\infty}\left(0, T ; L_{p}(G)\right), \quad U_{j}(x) \in W_{p}^{2}(G)(j=0,1), \\
\varphi, \varphi_{t}, \varphi_{t t} \in L_{p}\left(0, T ; W_{p}^{2-1 / p}(G)\right), \quad \alpha_{i} \in W_{p}^{2}(0, T), i=1,2, \ldots, r_{2}, \quad p>n .
\end{gathered}
$$

Then there exists a constant $\gamma_{0}>0$ such that there exists a unique solution $\left(U, c_{1}, \ldots, c_{r_{2}}\right)$ to $(1)-(3),(24)$ for $t \in\left[0, \gamma_{0}\right]$ such that

$$
U, U_{t} \in C\left(\left[0, \gamma_{0}\right] ; W_{p}^{2}(G)\right), \quad U_{t t} \in L_{p}\left(0, \gamma_{0} ; W_{p}^{2}(G)\right), \quad c_{i}(t) \in L_{p}\left(0, \gamma_{0}\right)\left(i=1,2, \ldots, r_{2}\right) .
$$

Proof. Let $\Phi$ be a solution to the problem (see Theorem 2)

$$
L_{0} \Phi_{t t}=f_{0},\left.\quad \Phi\right|_{t=0}=U_{0},\left.\Phi_{t}\right|_{t=0}=U_{1},\left.\Phi\right|_{S}=\varphi .
$$

We have that $\Phi, \Phi_{t} \in C\left([0, T] ; W_{p}^{2}(G)\right), \Phi_{t t} \in L_{p}\left(0, T ; W_{p}^{2}(G)\right)$. Without loss of generality we can assume that (26) is fulfilled with this function $\Phi$. Then the function $V=U-\Phi$ is a solution to the problem

$$
L_{0} V_{t t}+L_{1} V_{t}+L_{2} V=\sum_{i=1}^{r_{0}} c_{i}(t) f_{i}(x, t)-\sum_{i=r_{0}+1}^{r_{1}} c_{i}(t) L^{i} \Phi_{t}-\sum_{i=r_{1}+1}^{r_{2}} c_{i}(t) L^{i} \Phi
$$




$$
\left.V\right|_{t=0}=0,\left.\quad V\right|_{S}=0, \quad V\left(x_{j}, t\right)=\alpha_{j}(t)-\Phi\left(x_{j}, t\right)=\tilde{\alpha}_{j}(t) .
$$

We have that $\Phi \in W_{p}^{2}\left(G ; W_{p}^{2}(0, T)\right)$ and thus $\Phi \in C^{1}\left(\bar{G} ; W_{p}^{2}(0, T)\right)$ after possible modification on a set of zero measure (see, for instance, (5.4) in [25]). In particular, $\Phi\left(x_{i}, \cdot\right) \in W_{p}^{2}(0, T)$ and thereby $\tilde{\alpha}_{j} \in W_{p}^{2}(0, T)\left(j=1,2, . ., r_{2}\right)$. Inverting $L_{0}$ in $(28)$, we arrive at the equality

$$
V_{t t}+L_{0}^{-1}\left(L_{1} \partial_{t}+L_{2}\right) V=\sum_{i=1}^{r_{0}} c_{i}(t) L_{0}^{-1} f_{i}(x, t)-\sum_{i=r_{0}+1}^{r_{1}} c_{i}(t) L_{0}^{-1} L^{i} \Phi_{t}-\sum_{i=r_{1}+1}^{r_{2}} c_{i}(t) L_{0}^{-1} L^{i} \Phi .
$$

Note that the traces $L_{0}^{-1} L^{i} \Phi_{t}\left(x_{j}, t\right)\left(i=r_{0}+1, \ldots, r_{1}\right), L_{0}^{-1} L^{i} \Phi\left(x_{j}, t\right)\left(i=r_{1}+1, \ldots, r_{2}\right)$ are defined for almost al $t$ and every of these functions belongs to $L_{\infty}(0, T)$. Indeed, we have $L_{0}^{-1} L^{i} \Phi_{t} \in W_{p}^{2}\left(G ; L_{p}(0, T)\right)$ and thus there exists the trace $[25,(5.4)], L_{0}^{-1} L^{i} \Phi_{t}\left(x_{j}, \cdot\right) \in$ $L_{p}(0, T)$. For almost all $t$, we have

$$
\left|L_{0}^{-1} L^{i} \Phi_{t}\left(x_{j}, t\right)\right| \leq c\left\|L^{i} \Phi_{t}(x, t)\right\|_{L_{p}(G)} \leq c_{1}\left\|\Phi_{t}(x, t)\right\|_{W_{p}^{2}(G)} .
$$

Therefore,

$$
\| L_{0}^{-1} L^{i} \Phi_{t}\left(x_{j}, t\left\|_{L_{\infty}(0, T)} \leq c\right\| \Phi_{t} \|_{L_{\infty}\left(0, T ; W_{p}^{2}(G)\right)}, \quad i=r_{0}+1, \ldots, r_{1} .\right.
$$

Similarly we can prove that $L_{0}^{-1} L^{i} \Phi\left(x_{j}, \cdot\right) \in L_{\infty}(0, T)\left(i=r_{1}+1, \ldots, r_{2}\right)$ and $L_{0}^{-1} f_{i}\left(x_{j}, \cdot\right) \in$ $L_{\infty}(0, T)$. Take $x=x_{j}$ in (30). In view of $(24)$, we obtain that

$$
\begin{aligned}
\tilde{\alpha}_{j t t}+ & L_{0}^{-1}\left(L_{01} \partial_{t}+L_{02}\right) V\left(x_{j}, t\right)+\sum_{i=r_{0}+1}^{r_{1}} c_{i}(t) L_{0}^{-1} L^{i} V_{t}\left(x_{j}, t\right)+\sum_{i=r_{1}+1}^{r_{2}} c_{i}(t) L_{0}^{-1} L^{i} V\left(x_{j}, t\right) \\
& =\sum_{i=1}^{r_{0}} c_{i}(t) L_{0}^{-1} f_{i}\left(x_{j}, t\right)-\sum_{i=r_{0}+1}^{r_{1}} c_{i}(t) L_{0}^{-1} L^{i} \Phi_{t}\left(x_{j}, t\right)-\sum_{i=r_{1}+1}^{r_{2}} c_{i}(t) L_{0}^{-1} L^{i} \Phi\left(x_{j}, t\right),
\end{aligned}
$$

where $j=1,2, . ., r_{2}$. Equalities (32) can be written in the form

$$
B \vec{c}=\left(\begin{array}{c}
\beta_{1}+R_{1}(\vec{c}) \\
\cdots \\
\cdots \\
\beta_{r_{2}}+R_{r_{2}}(\vec{c}),
\end{array}\right), \vec{\beta}=\left(\begin{array}{c}
\beta_{1} \\
\cdots \\
\cdots \\
\beta_{r_{2}}
\end{array}\right), \beta_{i}=\tilde{\alpha}_{i t t}
$$

where $\quad R_{k}(\vec{c})=L_{0}^{-1}\left(L_{01} \partial_{t}+L_{02}\right) V\left(x_{k}, t\right)+\sum_{i=r_{0}+1}^{r_{1}} c_{i}(t) L_{0}^{-1} L^{i} V_{t}\left(x_{k}, t\right)+$ $\sum_{i=r_{1}+1}^{r_{2}} c_{i}(t) L_{0}^{-1} L^{i} V\left(x_{k}, t\right)$. Thus, we arrive at the operator equation

$$
\vec{c}=\vec{c}=B^{-1}\left(\begin{array}{c}
\beta_{1}+R_{1}(\vec{c}) \\
\cdots \\
\cdots \\
\beta_{r_{2}}+R_{r_{2}}(\vec{c}),
\end{array}\right)=R(\vec{c}) .
$$

The right-hand side is an operator $R(\vec{c})$ taking the vector $\vec{c}(t)$ into the right-hand side of $(33)$, with $V(x, t)$ a solution to (28). Study the properties of this operator. Fix $R_{0}=$ $2\left\|B^{-1} \vec{\beta}\right\|_{L_{p}(0, T)}$. By construction, $\tilde{\alpha}_{i t t} \in L_{p}(0, T)$. Since the entries of the matrix $B$ belong 
to $L_{\infty}(0, T)$, we have $B^{-1} \vec{\beta} \in L_{p}(0, T)$. Theorem 2 implies that, for every vector-function $\vec{c}(t) \in B_{R_{0}}=\left\{\vec{c} \in L_{p}(0, T):\|\vec{c}\|_{L_{p}(0, T)} \leq R_{0}\right\}$, the problem

$$
\begin{gathered}
L_{0} V_{t t}+\left(L_{1} \partial_{t}+L_{2}\right) V=\sum_{i=1}^{r_{0}} c_{i}(t) f_{i}(x, t)-\sum_{i=r_{0}+1}^{r_{1}} c_{i}(t) L^{i} \Phi_{t}-\sum_{i=r_{1}+1}^{r_{2}} c_{i}(t) L^{i} \Phi \\
\left.V\right|_{t=0}=0,\left.\quad V_{t}\right|_{t=0}=0,\left.\quad V\right|_{S}=0
\end{gathered}
$$

has a unique solution. For $\lambda>0$, we have the estimates

$$
\sup _{t} e^{-\lambda t}\|V(t, x)\|_{W_{p}^{2}(G)} \leq \frac{1}{|\lambda|^{1 / q}}\left(\int_{0}^{T}\left\|V_{t}\right\|_{W_{p}^{2}(G)}^{p} e^{-\lambda t p} d t\right)^{1 / p}, 1 / p+1 / q=1 .
$$

In view of (35) and (34), we infer

$$
\begin{gathered}
\|\| V_{t t}\left\|_{W_{p}^{2}(G)} e^{-\lambda t}\right\|_{L_{p}(0, T)} \leq c\left(\|\|\left(L_{1} \partial_{t}+L_{2}\right) V\left\|_{L_{p}(G)} e^{-\lambda t}\right\|_{L_{p}(0, T)}+\right. \\
\left.+\|\| \sum_{i=1}^{r_{0}} c_{i}(t) f_{i}(x, t)-\sum_{i=r_{0}+1}^{r_{1}} c_{i}(t) L^{i} \Phi_{t}-\sum_{i=r_{1}+1}^{r_{2}} c_{i}(t) L^{i} \Phi\left\|_{L_{p}(G)} e^{-\lambda t}\right\|_{L_{p}(0, T)}\right) \leq \\
\leq \frac{c_{0}}{|\lambda|^{1 / q}}\left(\|\vec{c}\|_{L_{p}(0, T)}+1\right)\left\|V_{t t} e^{-\lambda t}\right\|_{L_{p}\left(0, T ; W_{p}^{2}(G)\right)}+c_{1}\|\vec{c}\|_{L_{p}(0, T)},
\end{gathered}
$$

where the constant $c_{0}$ is independent of $\lambda$. Choosing sufficiently large $\lambda>0$ and estimating the quantity $\|\vec{c}\|_{L_{p}(0, T)}$ by $R_{0}$, we obtain that

$$
\left\|V_{t t}\right\|_{L_{p}\left(0, T ; W_{p}^{2}(G)\right)}+\left\|V_{t}\right\|_{L_{p}\left(0, T ; W_{p}^{2}(G)\right)}+\|V\|_{L_{p}\left(0, T ; W_{p}^{2}(G)\right)} \leq c_{2}\|\vec{c}\|_{L_{p}(0, T)} \leq c\left(R_{0}\right)
$$

where $c\left(R_{0}\right)$ is independent of $\vec{c} \in B_{R_{0}}$. Proceed with further estimates. Let $\vec{c}^{1}, \vec{c}^{2} \in B_{R_{0}}$ and let $V^{1}, V^{2}$ be respective solutions to (34). Thus, we infer

$$
\begin{aligned}
& L_{0} V_{t t}^{i}+\left(L_{01} \partial_{t}+L_{02}\right) V^{i}+\sum_{j=r_{0}+1}^{r_{1}} c_{j}^{i}(t) L^{j} V_{t}^{i}+\sum_{j=r_{1}+1}^{r_{2}} c_{j}^{i}(t) L^{j} V^{i}= \\
& \quad=\sum_{j=1}^{r_{0}} c_{j}^{i}(t) f_{i}(x, t)-\sum_{j=r_{0}+1}^{r_{1}} c_{j}^{i}(t) L^{j} \Phi_{t}-\sum_{j=r_{1}+1}^{r_{2}} c_{j}^{i}(t) L^{j} \Phi
\end{aligned}
$$

Note that the functions $V^{i}$ satisfy (37). Subtracting equalities (38) for $i=1,2$ and denoting $\omega=V^{1}-V^{2}$, we derive that

$$
\begin{gathered}
L_{0} \omega_{t t}+\left(L_{01} \partial_{t}+L_{02}\right) \omega+\sum_{j=r_{0}+1}^{r_{1}} c_{j}^{1}(t) L^{j} \omega_{t}+\sum_{j=r_{1}+1}^{r_{2}} c_{j}^{1}(t) L^{j} \omega= \\
=\sum_{j=1}^{r_{0}}\left(c_{j}^{1}-c_{j}^{2}\right)(t) f_{i}(x, t)-\sum_{j=r_{0}+1}^{r_{1}}\left(c_{j}^{1}-c_{j}^{2}\right)(t) L^{j} V_{t}^{2}- \\
-\sum_{j=r_{1}+1}^{r_{2}}\left(c_{j}^{1}-c_{j}^{2}\right)(t) L^{j} V^{2}-\sum_{j=r_{0}+1}^{r_{1}}\left(c_{j}^{1}-c_{j}^{2}\right)(t) L^{j} \Phi_{t}-\sum_{j=r_{1}+1}^{r_{2}}\left(c_{j}^{1}-c_{j}^{2}\right)(t) L^{j} \Phi .
\end{gathered}
$$

Inequality (37) and the previous arguments validate the estimate

$$
\left\|\omega_{t t}\right\|_{L_{p}\left(0, T ; W_{p}^{2}(G)\right)}+\|\omega\|_{L_{p}\left(0, T ; W_{p}^{2}(G)\right)}+\left\|\omega_{t}\right\|_{L_{p}\left(0, T ; W_{p}^{2}(G)\right)} \leq c_{2}\left\|\overrightarrow{c^{1}}-\overrightarrow{c^{2}}\right\|_{L_{p}(0, T)} .
$$

The arguments of Theorem 2 imply the estimate

$$
\left\|\omega_{t t}\right\|_{L_{p}\left(0, \gamma ; W_{p}^{2}(G)\right)}+\left\|\omega_{t}\right\|_{L_{p}\left(0, \gamma ; W_{p}^{2}(G)\right)}+\|\omega\|_{L_{p}\left(0, \gamma ; W_{p}^{2}(G)\right)} \leq c_{3}\left\|\overrightarrow{c^{1}}-\overrightarrow{c^{2}}\right\|_{L_{p}(0, \gamma)}
$$


valid for all $\gamma \in[0, T]$. The corresponding estimate of the form (37) is also true with a constant $c_{3}$ independent of $\gamma$. The estimate is valid for all $\vec{c}(t) \in B_{R_{0}, \gamma}=\{\vec{c}(t)$ : $\left.\|\vec{c}\|_{L_{p}(0, \gamma) \leq R_{0}}\right\}$. Proceed with the estimates for the operator $R$. The estimate (41) yields

$$
\begin{gathered}
\left\|R\left(c^{1}\right)-R\left(c^{2}\right)\right\|_{L_{p}(0, \gamma)} \leq c \sum_{j=1}^{r_{2}} \| L_{0}^{-1}\left(L_{01} \partial_{t}+L_{02}\right)\left(V^{1}-V^{2}\right)\left(x_{j}, t\right)+ \\
+\sum_{i=r_{0}+1}^{r_{1}} c_{i}^{1} L_{0}^{-1} L^{i} V_{t}^{1}\left(x_{j}, t\right)-\sum_{i=r_{0}+1}^{r_{1}} c_{i}^{2} L_{0}^{-1} L^{i} V_{t}^{2}\left(x_{j}, t\right)+\sum_{i=r_{1}+1}^{r_{2}} c_{i}^{1} L_{0}^{-1} L^{i} V^{1}\left(x_{j}, t\right)- \\
-\sum_{i=r_{1}+1}^{r_{2}} c_{i}^{2} L_{0}^{-1} L^{i} V^{2}\left(x_{j}, t\right) \|_{L_{p}(0, \gamma)} \leq \sum_{j=1}^{r_{2}}\left(\| \sum_{i=r_{0}+1}^{r_{1}}\left(c_{i}^{1}-c_{i}^{2}\right)(t) L_{0}^{-1} L^{i} V_{t}^{1}\left(x_{j}, t\right)+\right. \\
+\sum_{i=r_{1}+1}^{r_{2}}\left(c_{i}^{1}-c_{i}^{2}\right)(t) L_{0}^{-1} L^{i} V^{1}\left(x_{j}, t\right)\left\|_{L_{p}(0, \gamma)}+\right\| \sum_{i=r_{0}+1}^{r_{1}} c_{i}^{2}\left(L_{0}^{-1} L^{i}\left(V_{t}^{1}-V_{t}^{2}\right)\left(x_{j}, t\right)\right)+ \\
\left.+\sum_{i=r_{1}+1}^{r_{2}}\left(c_{i}^{2} L_{0}^{-1} L^{i}\left(V^{1}-V^{2}\right)\left(x_{j}, t\right)\right) \|_{L_{p}(0, \gamma)}\right)+c_{4}\left\|\overrightarrow{c^{1}}-\overrightarrow{c^{2}}\right\|_{L_{p}(0, \gamma)} .
\end{gathered}
$$

Estimate the summands on the right-hand side as follows:

$$
\begin{aligned}
& \left\|\left(c_{i}^{1}-c_{i}^{2}\right) L_{0}^{-1} L^{i} V_{t}^{1}\left(x_{j}, t\right)\right\|_{L_{p}(0, \gamma)} \leq\left\|c_{i}^{1}-c_{i}^{2}\right\|_{L_{p}(0, \gamma)}\left\|L_{0}^{-1} L^{i} V_{t}^{1}\left(x_{j}, t\right)\right\|_{L_{\infty}(0, \gamma)}, \\
& \left\|\left(c_{i}^{1}-c_{i}^{2}\right) L_{0}^{-1} L^{i} V^{1}\left(x_{j}, t\right)\right\|_{L_{p}(0, \gamma)} \leq\left\|c_{i}^{1}-c_{i}^{2}\right\|_{L_{p}(0, \gamma)}\left\|L_{0}^{-1} L^{i} V^{1}\left(x_{j}, t\right)\right\|_{L_{\infty}(0, \gamma)} .
\end{aligned}
$$

The embedding theorems and Theorem 1 imply that

$$
\begin{aligned}
& \left\|L_{0}^{-1} L^{i} V_{t}^{1}\left(x_{j}, t\right)\right\|_{L_{\infty}(0, \gamma)} \leq c\left\|V_{t}^{1}(x, t)\right\|_{L_{\infty}\left(0, \gamma ; W_{p}^{2}(G)\right)}, \leq c \gamma^{1 / q}\left\|V_{t t}^{1}\right\|_{L_{p}\left(0, \gamma ; W_{p}^{2}(G)\right)} \quad\left(\frac{1}{q}+\frac{1}{p}=1\right) . \\
& \left\|L_{0}^{-1} L^{i} V^{1}\left(x_{j}, t\right)\right\|_{L_{\infty}(0, \gamma)} \leq c\left\|V^{1}(x, t)\right\|_{L_{\infty}\left(0, \gamma ; W_{p}^{2}(G)\right)}, \leq c \gamma^{1 / q}\left\|V_{t}^{1}\right\|_{L_{p}\left(0, \gamma ; W_{p}^{2}(G)\right)} \quad\left(\frac{1}{q}+\frac{1}{p}=1\right) .
\end{aligned}
$$

Hence, we have the estimates

$$
\begin{aligned}
& \left\|\left(c_{i}^{1}-c_{i}^{2}\right) L_{0}^{-1} L^{i} V_{t}^{1}\left(x_{j}, t\right)\right\|_{L_{p}(0, \gamma)} \leq c_{1} \gamma^{1 / q}\left\|\overrightarrow{c^{1}}-\overrightarrow{c^{2}}\right\|_{L_{p}(0, \gamma)}, \\
& \left\|\left(c_{i}^{1}-c_{i}^{2}\right) L_{0}^{-1} L^{i} V^{1}\left(x_{j}, t\right)\right\|_{L_{p}(0, \gamma)} \leq c_{1} \gamma^{1 / q}\left\|\overrightarrow{c^{1}}-\overrightarrow{c^{2}}\right\|_{L_{p}(0, \gamma)},
\end{aligned}
$$

where the constant $c_{1}$ depends on $R_{0}$ and is independent of $\gamma$. Similarly, employing (41) we obtain that

$$
\begin{gathered}
\left\|c_{i}^{2}\left(L_{0}^{-1} L^{i}\left(V_{t}^{1}\left(x_{j}, t\right)-V_{t}^{2}\left(x_{j}, t\right)\right)\right)\right\|_{L_{p}(0, \gamma)} \leq R_{0} c\left\|V_{t}^{1}(x, t)-V_{t}^{2}(x, t)\right\|_{L_{\infty}\left(0, \gamma ; W_{p}^{2}(G)\right)} \leq \\
\leq R_{0} c \gamma^{1 / q}\left\|V_{t t}^{1}-V_{t t}^{2}\right\|_{L_{p}\left(0, \gamma ; W_{p}^{2}(G)\right)} \leq c_{1} \gamma^{1 / q}\left\|\overrightarrow{c^{1}}-\overrightarrow{c^{2}}\right\|_{L_{p}(0, \gamma)} . \\
\left\|c_{i}^{2}\left(L_{0}^{-1} L^{i}\left(V^{1}\left(x_{j}, t\right)-V^{2}\left(x_{j}, t\right)\right)\right)\right\|_{L_{p}(0, \gamma)} \leq R_{0} c\left\|V^{1}(x, t)-V^{2}(x, t)\right\|_{L_{\infty}\left(0, \gamma ; W_{p}^{2}(G)\right)} \leq \\
\leq R_{0} c \gamma^{1 / q}\left\|V_{t}^{1}-V_{t}^{2}\right\|_{L_{p}\left(0, \gamma ; W_{p}^{2}(G)\right)} \leq c_{1} \gamma^{1 / q}\left\|\overrightarrow{c^{1}}-\overrightarrow{c^{2}}\right\|_{L_{p}(0, \gamma)} .
\end{gathered}
$$

In accordance with $(42)-(46)$, we conclude that

$$
\left\|R\left(c^{1}\right)-R\left(c^{2}\right)\right\|_{L_{p}(0, \gamma)} \leq c \gamma^{1 / q}\left\|\overrightarrow{c^{1}}-\overrightarrow{c^{2}}\right\|_{L_{p}(0, \gamma)} .
$$

Choose $\gamma_{0}: c \gamma_{0}^{1 / q}=1 / 2$. In this case for $c^{1}, c^{2} \in B_{R_{0}, \gamma}$ with $\gamma \leq \gamma_{0}$ we have inequality (47). Moreover, $R(\vec{c})=R(\vec{c})-R(0)+R(0)$ and

$$
\|R(\vec{c})\|_{L_{q}(0, \gamma)} \leq\|R(0)\|_{L_{q}(0, \gamma)}+\frac{1}{2}\|\vec{c}\|_{L_{q}(0, \gamma)} \leq \frac{R_{0}}{2}+\frac{R_{0}}{2}=R_{0}
$$


Thus, $R$ takes the ball $B_{R_{0}, \gamma_{0}}$ into itself and contractive. The fixed point theorem ensures the solvability of (34). The facts that $V$ is a solution to (28) and satisfies conditions (29) can be proven as in the linear case.

The authors were supported by RFBR (Grant no. 15-01-06582).

\section{References}

1. Sobolev S.L. [On a New Problem of Mathematical Physics]. Izvestiya: Mathematics, 1954, vol. 18, pp. 3-50. (in Russian)

2. Boussinesq J.V. Essai sur la theorie des eaux courantes. Mem. Pesentes Divers Savants Acad. Sci. Inst. France, 1877, vol. 23, pp. 1-680.

3. Love A.E.H. A Treatise on the Mathematical Theory of Elasticity. New York, Dover Publications, 1944.

4. Sveshnikov A.G., Alshin A.B., Korpusov M.O., Pletner U.D. Linear and Non-Linear Equations Sobolev's Type. Moscow, Fizmatlit, 2007. 736 p. (in Russian)

5. Ikezi H. Experimental Study of Solitons in Plasma. In Solitons in Action, N.Y., Academic Press, 1978, pp. 163-184.

6. Lyubanova A.Sh. Identification of a Coefficient in the Leading Term of a Pseudoparabolic Equation of Filtration. Journal of Applied and Industrial Mathematics, 2013, vol. 54, no. 6, pp. 1046-1058. DOI: $10.1134 / \mathrm{s} 0037446613060116$

7. Lyubanova A.Sh., Tani A. On Inverse Problems for Pseudoparabolic and Parabolic Equations of Filtration. Inverse Problems in Science and Engineering, 2011, vol. 19, no. 7, pp. 1023-1042. DOI: 10.1080/17415977.2011.569712

8. Kozhanov A.I. [On Solvability of Inverse Problems of Recovering the Coefficients in Composite Type Equations]. Vestnik Novosibirskogo gosudarstvennogo universiteta. Seriya Matematika, Mekhanika, Informatika, 2008, vol. 8, no. 3, pp. 81-99. (in Russian)

9. Kozhanov A.I. Nonlinear Loaded Equations and Inverse Problems. Computational Mathematics and Mathematical Physics, 2004, vol. 44, no. 4, pp. 657-675.

10. Kozhanov A.I. [On Solvability of Inverse Coefficient for Some Sobolev-Type Equations]. Belgorod State University Scientific Bulletin. Mathematics. Physics. 2010, vol. 18, no. 5, pp. $88-98$.

11. Fedorov V.E., Urazaeva A.V. An Inverse Problem for Linear Sobolev Type Equations. Journal of Inverse and Ill-Posed Problems, 2004, vol. 12, no. 4, pp. 387-395. DOI: $10.1515 / 1569394042248210$

12. Ablabekov B.S. Obratnye zadachi dlya psevdoparabolicheskikh uravneniy [Inverse Problems for Pseudoparabolic Equations]. Bishkek, Ilim, 2001. (in Russian)

13. Asanov A., Atamanov E.R. An Inverse Problem for a Pseudoparabolic Integro-Defferential Operator Equation. Siberian Mathematical Journal, 1995, vol. 38, no. 4, pp. 645-655. DOI: $10.1007 / \mathrm{BF} 02107322$

14. Favini A, Lorenzi A. Differential Equations: Inverse and Direct Problems. Boca Raton, London, N.Y., Chapman and Hall/CRC, 2006. 304 p. DOI: 10.1201/9781420011135

15. Zamyshlyaeva A.A., Tsyplenkova O.N. The Optimal Control over Solutions of the InitialFinish Value Problem for the Boussinesque - Love Equation. The Bulletin of the South Ural State University. Series: Mathematical Modelling, Programming and Computer Software, 2012, no. 5 (264), pp. 13-24. (in Russian) 
16. Zamyshlyaeva A.A., Yuzeeva A.V. The Initial-Finish Value Problem for the Boussinesq - Love Equation. The Bulletin of the South Ural State University. Series: Mathematical Modelling, Programming and Computer Software, 2010, no. 16 (192), pp. 23-31. (in Russian)

17. Zamyshlyaeva A.A., Tsyplenkova O.N. Optimal Control of Solutions of the Showalter Sidorov - Dirichlet Problem for the Boussinesq - Love Equation. Differential Equations, 2013, vol. 49, no. 11, pp. 1356-1365. DOI: 10.1134/S0012266113110049

18. Mehraliyev Ya.T. Inverse Problem of the Boussinesq - Love Equation with an Extra Integral Condition. Journal of Applied and Industrial Mathematics, 2013, vol. 16, no. 1 (53), pp. 75-83.

19. Mehraliyev Ya.T. On Solvability of an Inverse Boundary Value Problem for the Boussinesq - Love Equation. Journal of Siberian Federal University. Mathematics and Physics, 2013, vol. 6 , no. 4 , pp. 485-494.

20. Ablabekov B.S., Kasymalieva A.A. [An Inverse Problem of Recovering the Right-Hand Side for the Boussinesq - Love Equation]. Abstracts of the Second International Scientific Conference "Theory and Numerical Methods of Solving Inverse and Ill-Posed Problems", September 21-29, 2010, Novosibirsk, Sobolev Institute of Mathematics, 2010, pp. 2-4. (in Russian)

21. Ladyzhenskaya O.A, Ural'tseva N.N. Lineynye i kvazilineynye uravneniya ellipticheskogo tipa [Linear and Quasilinear Elliptic Equations]. Moscow, Nauka, 1964. (in Russian)

22. Gilbarg D., Trudinger N. Elliptic Differential Equation with Partial Derivative of the Second Order. Berlin, Heidelberg, Springer-Verlag, 2001.

23. Pyatkov S.G., Shergin S.N. On Some Mathematical Models of Filtration Theory. The Bulletin of the South Ural State University. Series: Mathematical Modelling, Programming and Computer Software, 2015, vol. 8, no. 2, pp. 105-116.

24. Amann H. Compact Embeddings of Vector-Valued Sobolev and Besov Spaces. Glasnik matematicki, 2000, vol. 35, no. 1, pp. 161-177.

25. Amann H. Operator-Valued Foutier Multipliers, Vector-Valued Besov Spaces and Applications. Mathematische Nachrichten, 1997, vol. 186, no. 1, pp. 5-56. DOI: $10.1002 /$ mana.3211860102

Received March 3, 2016

УДК 517.95

DOI: $10.14529 / \mathrm{mmp} 160207$

\title{
ОБРАТНЫЕ ЗАДАЧИ ДЛЯ МАТЕМАТИЧЕСКИХ МОДЕЛЕЙ СОБОЛЕВСКОГО ТИПА
}

\author{
С.Г. Пятков, С.Н. Шергин
}

\begin{abstract}
Работа посвящена рассмотрению обратных задач для ряда математических моделей, основанных на уравнениях и системах Соболевского типа, возникающих в динамике стратифицированной жидкости, теории упругости, гидродинамике, электродинамике и других областях. Вместе с решением определяются неизвестная правой части и коэффициенты в уравнении типа Соболева четвертого порядка. В качестве условия переопределения берутся значения решения в отдельных точках пространственной области. Задача сводится к некоторому операторному уравнению, разрешимость которого устанавливается при помощи априорных оценок и теоремы о неподвижной точке.
\end{abstract}


Доказываются теоремы о существовании и единственности решения поставленной задачи для линейного и нелинейного случая. В линейном случае результат является глобальным по времени, а в нелинейном локальным по времени. В качестве основных пространств рассматриваются пространства С.Л. Соболева.

Ключевые слова: модели соболевского типа; уравнение Соболева; математическая модель; теорема существования и единственности решения; обратная задача; краевая задача; волны в плазме; вращающаяся жидкость; модель Буссинеска - Ллва.

\section{Литература}

1. Соболев, С.Л. Об одной новой задаче математической физики / С.Л. Соболев // Известия Российской академии наук. Серия математическая. - 1954. - Т. 18. - С. 3-50.

2. Boussinesq, J.V. Essai sur la theorie des eaux courantes / J.V. Boussinesq // Mem. Pesentes Divers Savants Acad. Sci. Inst. France. - 1877. - № 23. - P. 1-680.

3. Love, A.E.H. A Treatise on the Mathematical Theory of Elasticity. - N.Y.: Dover Publications, 1944.

4. Линейные и нелинейные уравнения Соболевского типа / А.Г. Свешников, А.Б. Альшин, М.О. Корпусов, Ю.Д. Плетнер. - М.: Физматлит, 2007. - 736 с.

5. Икези, Х. Экспериментальное исследование солитонов в плазме / Х. Икези // Солитоны в действии. - М.: Мир, 1981. - С. 163-184.

6. Любанова, А.Ш. Идентификация коэффициента в старшем члене псевдопараболического уравнения типа фильтрации / А.Ш. Любанова / Сибирский журнал индустриальной математики. - 2013. - Т. 54, № 6. - С. 1315-1330.

7. Lyubanova, A.Sh. On Inverse Problems for Pseudoparabolic and Parabolic Equations of Filtration / A.Sh. Lyubanova, A. Tani // Inverse Problems in Science and Engineering. - 2011. - V. 19, № 7. - P. 1023-1042.

8. Кожанов, А.И. О разрешимости обратных задач восстановления коэффициентов в уравнениях составного типа / А.И. Кожанов // Вестник Новосибирского государственного университета. Серия: математика, механика, информатика. - 2008. - Т. 8, № 3. - С. 81-99.

9. Кожанов, А.И. Нелинейные погруженные уравнения и обратные задачи / А.И. Кожанов // Журнал вычислительной математики и математической физики. - 2004. - Т. 44, № 4. - С. 694-716.

10. Кожанов, А.И. О разрешимости коэффициентных обратных задач для некоторых уравнений соболевского типа / А.И. Кожанов // Научные ведомости Белгородского государственного университета. Математика. Физика. - 2010. - Т. 18, № 5. - С. 88-98.

11. Fedorov, V.E. An Inverse Problem for Linear Sobolev Type Equations / V.E. Fedorov, A.V. Urazaeva // Journal of Inverse and Ill-Posed Problems. - 2004. - V. 12, № 4. P. $387-395$.

12. Аблабеков, Б.С. Обратные задачи для псевдопараболических уравнений / Б.С. Аблабеков. - Бишкек: Илим, 2001.

13. Asanov, A. An Inverse Problem for a Pseudoparabolic Integro-Defferential Operator Equation / A. Asanov, E.R. Atamanov // Siberian Mathematical Journal. - 1995. - V. 38, № 4. P. $645-675$.

14. Favini, A. Differential Equations: Inverse and Direct Problems / A. Favini, A. Lorenzi.-Boca Raton; London; N.Y.: Chapman and Hall/CRC, 2006. - 304 p.

15. Замышляева, А.А. Оптимальное управление решениями начально-конечной задачи для уравнения Буссинеска - Лява / А.А. Замышляева, О.Н. Цыпленкова // Вестник ЮУрГУ. Серия: Математическое моделирование и программирование. - 2012. - № 5 (264), вып. 11. - С. 13-24. 
16. Замышляева, А.А. Начально-конечная задача для уравнения Буссинеска-Лява / А.А. Замышляева, А.В. Юзеева // Вестник ЮУрГУ. Серия: Математическое моделирование и программирование. - 2010. - № 16 (192), вып. 5. - С. 23-31.

17. Замышляева, А.А. Оптимальное управление решениями задачи Шоуолтера - Сидорова - Дирихле для уравнения Буссинеска - Лява / А.А. Замышляева, О.Н. Цыпленкова // Дифференциальные уравнения. - 2013. - Т. 49, № 11. - С. 1390-1398.

18. Мегралиев, Я.Т. Обратная краевая задача для уравнения Буссинеска - Лява с дополнительным интегральным условием // Сибирский журнал индустриальной математики. 2013. - T. 16, № 1 (53). - C. 75-83.

19. Mehraliyev, Ya.T. On Solvability of an Inverse Boundary Value Problem for the Boussinesq - Love Equation / Ya.T. Mehraliyev // Journals of Siberian Federal University. Mathematics and Physics. - 2013. - V. 6, № 4. - P. 485-494.

20. Аблабеков, Б.С. Обратная задача восстановления правой части для уравнения Буссинеска - Лява / Б.С. Аблабеков, А.А. Касымалиева // Вторая международная научная школа-конференция «Теория и численные методы решения обратных и некорректных задач», 21-29 сентября 2010 г. - Новосибирск: Институт математики им. С.Л. Соболева CO PAH, 2010. - C. 2-4.

21. Ладыженская, О.А. Линейные и квазилинейные уравнения эллиптического типа / О.А. Ладыженская, Н.Н. Уральцева. - М.: Наука, 1973.

22. Гилбарг, Д. Эллиптические дифференциальные уравнения с частными производными второго порядка / Д. Гилбарг, Н. Трудингер. - М.: Наука, 1989.

23. Pyatkov, S.G. On Some Mathematical Models of Filtration Theory / S.G. Pyatkov, S.N. Shergin // Вестник ЮУрГУ. Серия: Математическое моделирование и программирование. - 2015. - Т. 8, № 2. - С. 105-116.

24. Amann, H. Compact Embeddings of Vector-Valued Sobolev and Besov Spaces / H. Amann // Glasnik matematicki. - 2000. - V. 35, № 1. - P. 161-177.

25. Amann, H. Operator-Valued Foutier Multipliers, Vector-Valued Besov Spaces and Applications / H. Amann // Mathematische nachrichten. - 1997. - V. 186, № 1. - P. 5-56.

Сергей Григорьевич Пятков, доктор физико-математических наук, профессор, кафедра «Высшая математика», Югорский государственный университет (г. ХантыМансийск, Российская Федерация), S_pyatkov@ugrasu.ru.

Сергей Николаевич Шергин, аспирант, кафедра «Высшая математика», Югорский государственный университет (г. Ханты-Мансийск, Российская Федерация), ssn@ugrasu.ru.

Поступила в редакиию 3 марта 2016 г. 